Research Article

\title{
Sample Preparation Methods Affect Engineering Characteristic Tests of Municipal Solid Waste
}

\author{
Dequan Kong $\mathbb{D}^{1}{ }^{1}$ Rong Wan, ${ }^{1,2}$ and Yonghui Wang ${ }^{1}$ \\ ${ }^{1}$ School of Civil Engineering, Chang'an University, Xi'an 710061, China \\ ${ }^{2}$ State Key Laboratory of Green Building in Western China, Xi'an University of Architecture \& Technology, Xi'an 710055, China
}

Correspondence should be addressed to Dequan Kong; dkong906@yahoo.com

Received 24 January 2020; Revised 5 May 2020; Accepted 4 June 2020; Published 26 June 2020

Academic Editor: Abdul Aziz bin Abdul Samad

Copyright $(0) 2020$ Dequan Kong et al. This is an open access article distributed under the Creative Commons Attribution License, which permits unrestricted use, distribution, and reproduction in any medium, provided the original work is properly cited.

The output of municipal solid waste (MSW) has sharply increased over the recent years, which induces many severe problems (environmental pollution, deteriorating human health, and increased land occupation). Engineering parameters form the research basis for MSW treatment, which can be greatly influenced by the applied sample preparation methods. Currently, the preparation method of MSW samples mostly refers to the geotechnical test standard. The suitability and accuracy of this method for MSW are less studied, especially when considering biodegradation, so further research is needed. Depending on whether the material is dried or remains wet during preparation, the samples made by traditional geotechnical test standards are referred to as dry method samples or wet method samples, respectively. To study the influence of the sample preparation methods on the MSW engineering properties of MSW, the compression tests, direct shear tests, and biodegradation compression tests were conducted for both types of samples (dry and wet). The results show that the data dispersion of the wet method samples is stronger. The average test data variance of wet samples was 1.43-8.85 times higher than that of dry samples. In both the direct shear test and the compression test, the differences in engineering parameters caused by the sample preparation method were less than $12.3 \%$ and $8.9 \%$, respectively. In biodegradation compression tests, the difference in engineering parameters reached up to $33.7 \%$. In general, the dry method is preferred for tests that do not consider biodegradation, while the wet method is more suitable for tests that consider biodegradation. The research can be used as a reference toward improving the simplicity and accuracy of MSW tests.

\section{Introduction}

With the development of global economy, population, and urbanization, the volume of produced municipal solid waste (MSW) increases rapidly. Globally, in 2018, there were 468, 392, 289, and 334 million tons of MSW generated by East Asian and Pacific states, Europe and Central Asia, North America, and South Asia [1]. MSW outputs in many areas are extremely high, and such an amount of MSW needs to be effectively treated.

China has the largest population and the fastest economic growth in the world. However, China also has a particularly prominent problem with MSW. The MSW production in China reached 2.28 million tons in 2018, which is $32.56 \%$ higher than that during 2013 , indicating an average annual growth rate of $6.51 \%$ [2]. This high volume of MSW exerts tremendous adverse effects on the urban landscape, environmental protection, and the health of residents. At present, the most widely used method to deal with MSW in China is sanitary landfill [3]. In 2018, China had more than 663 landfill facilities, which disposed of more than 1.17 billion tons of waste. The sanitary landfill is the most economical, convenient, and practical choice for China, and will thus continue to be vigorously applied for a long time [4].

Xi'an is a famous central city in western China. According to the Shaanxi Statistical Yearbook [5], the MSW outputs of Xi'an during 2009-2016 are presented in Table 1. The output of MSW of Xi'an almost doubled over the eight years, indicating an average annual growth rate of $11.7 \%$. 
TABle 1: Outputs of municipal solid waste (MSW) in Xi'an (ten thousand tons/year).

\begin{tabular}{lcccccccc}
\hline Year & 2009 & 2010 & 2011 & 2012 & 2013 & 2014 & 2015 & 2016 \\
\hline Output & 178.9 & 209.3 & 233.5 & 251.2 & 255.7 & 308.1 & 332.3 & 346.8 \\
\hline
\end{tabular}

However, until now, Xi'an has only one landfill (Jiangcungou landfill), which is far from meeting the requirements.

The physical and mechanical characteristics of MSW form an important basis for the design, construction, and maintenance of landfills. In situ tests and laboratory tests are important means to identify these engineering properties [6]. For laboratory tests, there are typically two sources where samples can be obtained. A number of researchers directly used original samples from landfill sites [7], while others used man-made samples for testing [8-10].

Though the use of original samples can directly reflect the actual characteristics of MSW, it has the disadvantages of high dispersion, poor sanitary conditions, and difficulty to control and adjust sample conditions. Although these cannot be identical to original samples, laboratory manmade MSW samples offer many advantages, such as relatively low dispersion, superior sanitary conditions, and strong controllability of material composition and parameters [11].

At present, there are a few standards for MSW laboratory tests. Examples are the Technical specification for soil test of landfilled municipal solid waste (CJJ/T204-2013) and the Technical code for geotechnical engineering of municipal solid waste sanitary landfill (CJJ176-2012) $[12,13]$. These codes directly use sample preparation methods of traditional geotechnical test standards, such as the preparation method of the Standard for soil test method (GB/T 50123-2019) [14]. When preparing samples, raw materials are dried at a temperature of $60-70^{\circ} \mathrm{C}$, and only then, water is added to arrive at the required water content. Because drying is part of the sample preparation, this sample preparation method is simply referred to as the "dry method."

A number of scholars studied the physical and mechanical properties by using the dry method (or a similar method) for sample preparation [15-18]. Although this sample preparation method has been used to conduct research, it is worth noting that MSW is a complex mixture with high organic matter content, high heterogeneity, and biodegradation properties, which differs from common soil. Whether the sample preparation methods of traditional geotechnical test standards are suitable for MSW has not been studied in detail.

To conduct this study, samples prepared by the dry method should be compared with original samples. Considering that the dispersion of samples taken from landfill is relatively large, the particle size and composition are very uneven and difficult to control. To ensure the validity of the comparison as well as consistency of the test conditions, this study used the manual quasioriginal sample to replace the original sample for tests. These quasioriginal samples were prepared according to the parameters of the waste components and water content obtained via on-site investigation. These components are then mixed and stirred until uniformity in the laboratory at their original water content. The formation process of this sample is similar to that of the landfill site sample and can reflect the engineering characteristics of the original sample to a large extent since its parameters and composition are more controllable. Because sample preparation involves no drying process, this type of sample preparation method is simply referred to as the "wet method."

The sample components of the wet method are mixed under their original water contents, while the dry method mixes dry components first and adds water later. Though this drying process exerts little effect on common soil, the high organic matter content of MSW and the drying process can destroy the degradation environment of the sample to a large extent. Therefore, this difference between wet method samples and dry method samples should not be ignored. Although test samples, prepared by the wet method or a similar method, were adopted by a number of scholars [19-23], most existing studies only provide a simple comparison of experimental data of individual samples. To date, no systematic research has been reported, especially under the background of biodegradation. Research on the influence of different sample preparation methods on the results of MSW laboratory tests is therefore necessary and meaningful.

This study conducted a field investigation on MSW in the Xi'an city and identified the composition and physical index of MSW. Both wet and dry method samples were prepared according to the results of field investigations. The engineering properties of both sample types were obtained by laboratory tests, and the differences are discussed. The effect of the sample preparation method on test results was analyzed. Suggestions are presented on how to select the most suitable sample preparation method for different laboratory tests of MSW.

\section{Field Investigation of Municipal Solid Waste}

Various factors affect the composition of MSW such as economic level, customs, climatic conditions, and geological conditions [24]. Therefore, MSW is a complex and variable mixture with specific characteristics and strong regionalism. At present, most research on MSW in China focuses on the eastern developed areas and a few large cities, while less research is conducted in Northwest China. Considering that Xi'an is a very important and typical city in Northwest China, it was selected as a representative example for MSW research.

To test the composition of MSW in the Xi'an city, seven waste collection stations were selected, based on the population distribution of the city, its urban layout, and the degree of development. The locations of these selected waste collection stations are shown in Figure 1, where Jiangcungou landfill, the only landfill of Xi'an, is also marked. The mass percentages of MSW compositions are listed in Table 2.

As shown in Table 2, the main components of MSW in Xi'an include soil, metal, plastics, food waste, paper, and fabric. Among these components, food waste, paper, and 


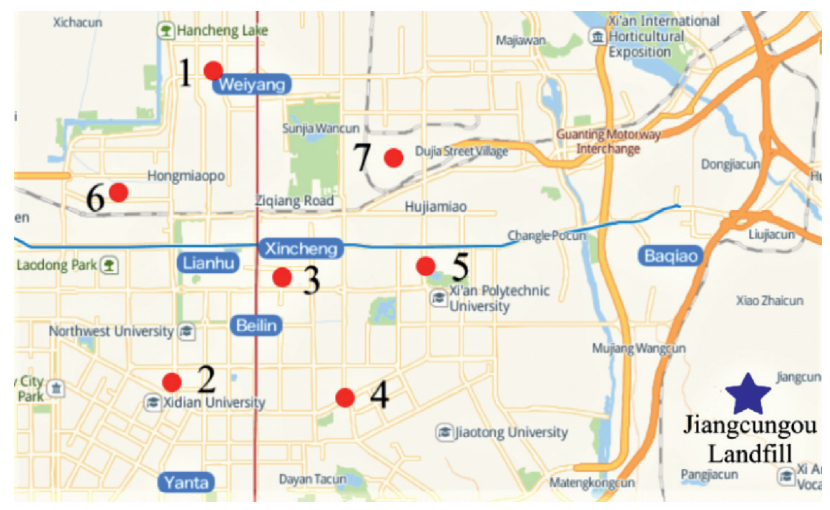
1. Jingkaiqu
5. Jiandonglu
2. Lianhuqu
6. Dabaiyang
3. Yuxianmen
7. Ziqianglu
4. Xingqinglu

FIGURE 1: Locations of waste collection stations in Xi'an where municipal solid waste (MSW) samples originated (the legend provides the names of the sample site).

TABle 2: Mass percentages of MSW compositions in Xi'an (\%).

\begin{tabular}{|c|c|c|c|c|c|c|c|}
\hline Waste collection stations & Soil & Food waste & Paper & Fabric & Plastics & Metal & Others \\
\hline Jingkaiqu & 48.3 & 28.0 & 10.3 & 3.4 & 7.6 & 2.1 & 0.3 \\
\hline Lianhuqu & 22.3 & 37.9 & 6.8 & 16.5 & 16.5 & 0.0 & 0.0 \\
\hline Yuxianmen & 48.4 & 22.8 & 11.4 & 7.0 & 8.8 & 1.6 & 0.0 \\
\hline Xingqinglu & 10.1 & 56.5 & 11.3 & 2.3 & 14.7 & 3.4 & 1.7 \\
\hline Jiandonglu & 26.2 & 46.3 & 9.5 & 7.4 & 9.5 & 1.1 & 0.0 \\
\hline Dabaiyang & 40.1 & 29.0 & 11.2 & 10.3 & 7.5 & 1.9 & 0.0 \\
\hline Ziqianglu & 28.2 & 40.6 & 8.3 & 9.4 & 12.5 & 1.0 & 0.0 \\
\hline Average value & 31.9 & 37.4 & 9.8 & 8.0 & 11.0 & 1.6 & 0.3 \\
\hline
\end{tabular}

fabric are degradable materials, and thus, the total mass percentage of degradable components across Xi'an reached $55.2 \%$. The average mass percentage of food waste was $37.4 \%$, which is the highest mass percentage component in this particular MSW. In general, the proportion of food waste is higher in more developed areas. For example, the proportion of food waste in Shanghai, Tianjin, and Shenzhen reaches up to $59 \%, 54 \%$, and $57 \%$, respectively [25]. Since Xi'an is less developed than Shanghai, Tianjin, and Shenzhen, the proportion of food waste is also comparatively low. Another main component of MSW is soil, with an average mass percentage of $31.9 \%$. Especially in areas like the Jingkai District, where large-scale infrastructure constructions are being built, the mass percentage of soil reached up to $48 \%$. The increase in such infrastructure projects causes a significant increase in soil in MSW.

The water contents and densities of the MSW of Xi' an are listed in Table 3. The water contents of MSW are generally high, and the differences between regions are large. The maximum measured value of water content was 2.6 times the minimum measured value. The maximum measured value of density was 1.7 times the minimum measured value. The density presented in Table 3 refers to the natural bulk density. The compaction density measured in the Jiangcungou landfill ranged between 1.06 and $1.75 \mathrm{~g} / \mathrm{cm}^{3}$ with an average value of $1.28 \mathrm{~g} / \mathrm{cm}^{3}$. Therefore, the compaction density is almost three times higher than the natural bulk density, indicating that the compressibility of fresh MSW is very high.

\section{Laboratory Test of Municipal Solid Waste}

3.1. Test Materials. Laboratory tests are an indispensable means to study MSW, and a reasonable sample preparation method is an important part of laboratory tests. All tests in this paper are in accordance with the Standard for Soil Test Method (GB/T 50123-2019) [14].

Based on field research and investigation, wet method samples and dry method samples were prepared, laboratory tests were conducted with both sample types, and the test results were compared and analyzed. The mass ratios of sample components are listed in Table 4, and the specific operation procedures are described as follows.

First, the mass percentage of each component was determined according to the average value result of filed investigations (shown in Table 2). For wet method samples, each component was prepared with its own water content, and then all components were added to the mixing container and stirred well. The particles size of the loess was less than $2.0 \mathrm{~mm}$, and the length of other components was less than 
TABLE 3: Water content and density of MSW in Xi'an.

\begin{tabular}{lcccccccc}
\hline Ingredients & Jingkaiqu & Lianhuqu & Yuxianmen & Xingqinglu & Jiandonglu & Dabaiyang & Ziqianglu & Average \\
\hline Water content $(\%)$ & 54.4 & 111.4 & 75.2 & 45.6 & 120.8 & 84.4 & 91.6 & 83.3 \\
Density $\left(\mathrm{g} / \mathrm{cm}^{3}\right)$ & 0.58 & 0.41 & 0.46 & 0.35 & 0.38 & 0.43 & 0.38 & 0.43 \\
\hline
\end{tabular}

TABLE 4: Mass ratios of sample components (\%).

\begin{tabular}{lcccccc}
\hline Ingredients & Soil & Kitchen waste & Paper & Fabric & Plastic & Metal \\
\hline Wet method & 32.2 & 37.4 & 9.8 & 8.0 & 11.0 & 1.6 \\
Dry method & 25.4 & 10.1 & 4.0 & 2.3 & 11.0 & 0.0 \\
\hline
\end{tabular}

$5.0 \mathrm{~mm}$. After mixing, the mixture was sealed and left to settle for $24 \mathrm{~h}$; then, the final water content was measured.

For dry method samples, the water content of each component and the final water content of the mixture were obtained from wet method samples. The dry mass of each component and the final total water mass of the mixture were calculated. All components were dried and then mixed in a preparation container. The calculated total amount of water was added and mixed well. The water content was measured after the mixture was sealed and left to settle for $24 \mathrm{~h}$. The particles size of the loess and the length of other components are identical to those of the wet method samples mentioned above.

If the difference between the measured water content and the predefined water content of a sample remained within the range of $\pm 1 \%$, the test was carried out [14]. Otherwise, the water content was adjusted to meet this requirement. The MSW sample mixtures, prepared by wet and dry methods, are shown in Figure 2. The physical indexes of the MSW sample were as follows: water content: $83.9 \%$, natural density: $1.2 \mathrm{~g} / \mathrm{cm}^{3}$, specific gravity: 2.1 , and void ratio: 2.2 .

In this study, direct shear test, compression test, and biodegradation compression test were conducted with both wet method samples and dry method samples. The engineering properties of both types of samples were obtained and discussed. The effects of sample preparation methods on test results were analyzed, and suggestions on how to select the appropriate sample preparation method in MSW laboratory tests are provided.

3.2. Direct Shear Test. The direct shear test was conducted with the ZJ automatic strain control-type direct shear instrument (Ningxi soil instrument company, Nanjing, China). The test method was consolidated slow shear. During the tests, four different vertical loads were applied, and shearing started when the compression deformation velocity of the sample was less than $0.01 \mathrm{~mm} / \mathrm{h}$. The shear speed was $0.02 \mathrm{~mm} / \mathrm{min}$ [14].

Over the course of the experiment, the shear strength lines of both sample types showed significant turning points at vertical loads of about $200 \mathrm{kPa}$. Therefore, to investigate the shear behavior of the samples in response to different vertical loads, the samples were tested at vertical stress ranges of $0-200 \mathrm{kPa}$ and $200-400 \mathrm{kPa}$, respectively. The data distribution of both methods in the direct shear test is shown in Figure 2. The shear strength variations of different samples under different vertical stress are listed in Table 5.

In the direct shear test, the dispersion of test data increased with increasing vertical stress. Under lower vertical stress, the dispersion of the wet method sample was smaller than that of the dry method sample. Under higher vertical stress, the dispersion of the wet method sample was significantly higher than that of the dry method sample. The test data average variance of wet method samples was 1.43 times higher than that of the dry method sample. The difference of average shear strength curves between both methods was small when the vertical stress remained below $200 \mathrm{kPa}$, and the shear strength parameters remained relatively similar. A significant turning trend of the test data was found for both types of samples when the vertical stress is near $200 \mathrm{kPa}$.

The shear strength envelope of each sample in direct shear tests is drawn in Figure 3. Table 6 shows the values of cohesion $c$ and angles of internal friction $\varphi$ for all samples. Because of the complexity of the MSW components, the shear strength indexes of different samples are obviously different, and sometimes, the difference between both sample types can be more than 10 folds.

For intuitive comparison, the average shear strength envelopes of different sample methods are shown in Figure 4. Table 7 lists the $c$ and $\varphi$ values of the average shear strength envelope. Interestingly, a significant difference was found in the dispersion of direct shear test data between both sample types, and the difference in the mean value was relatively small. At a vertical stress range $0-200 \mathrm{kPa}$, the shear strength envelope of the dry method sample was almost identical to that of the wet method sample. When the vertical stress range was $200-400 \mathrm{kPa}$, the cohesion $c$ of the dry method sample was $12.3 \%$ higher than that of the wet method sample, while not much difference was found for the internal friction angles $\varphi$ of both sample types.

In reference to relevant research [26-28] and combined with the tests of this study, the mechanism of shear strength of MSW was analyzed as follows. The MSW contains both granular materials and fibrous materials, and the total shear strength of the sample is composed of both the contribution of the friction by granular materials and the reinforcement by fibrous materials. For low vertical stress, the compactness 


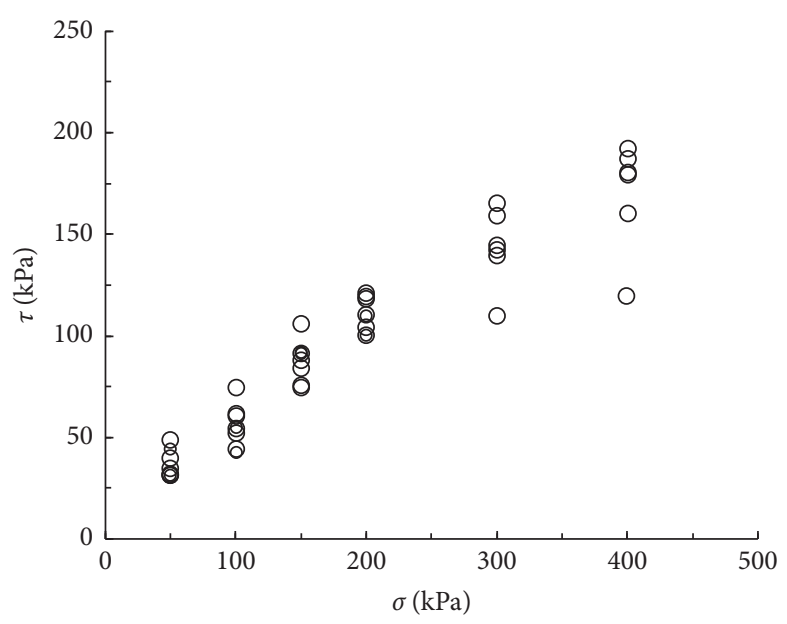

(a)

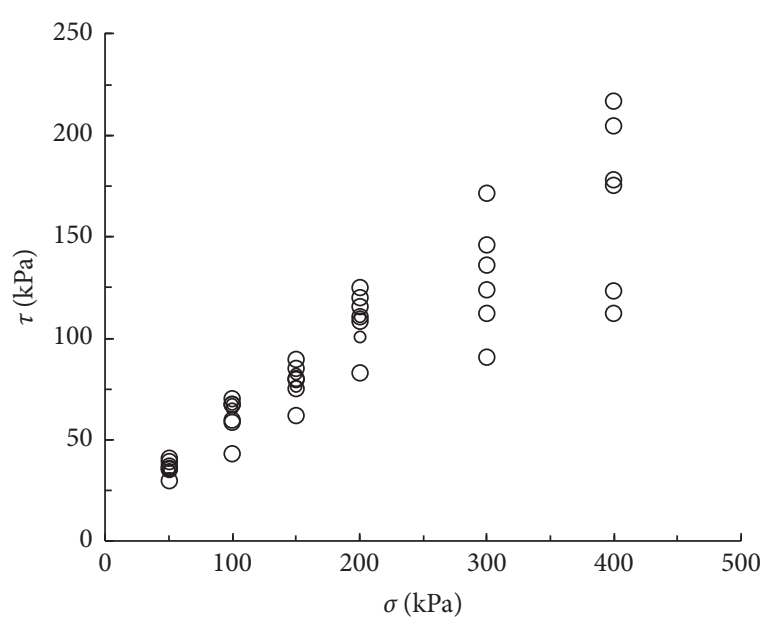

(b)

FIgURE 2: Data distribution of the direct shear test. (a) Wet method samples; (b) dry method samples.

TABLE 5: Shear strength variation of different samples under different vertical stress $\left(\times 10^{-2} \mathrm{kPa}^{2}\right)$.

\begin{tabular}{lcccccc}
\hline $\begin{array}{l}\text { Vertical stress } \\
(\mathrm{kPa})\end{array}$ & 50 & 100 & 150 & 200 & 300 & 400 \\
\hline $\begin{array}{l}\text { Wet method } \\
\text { samples }\end{array}$ & 9.64 & 69.21 & 61.00 & 144.57 & 652.89 & 1496.01 \\
$\begin{array}{l}\text { Dry method } \\
\text { samples }\end{array}$ & 40.91 & 89.75 & 89.36 & 61.93 & 312.57 & 608.05 \\
\hline
\end{tabular}

of MSW is relatively low, and the shear strength is mainly affected by the extrusion and the friction of granular materials. Therefore, the internal friction angle of the material at this stage is larger, while the cohesion is smaller. When the vertical stress increases, the sample is gradually compacted, the reinforcement effect caused by the fibrous material increases, and the cohesion of the material increases correspondingly. The shear strength of both types of samples changed significantly at a vertical stress of about $200 \mathrm{kPa}$. The internal friction angle of the sample was larger under low vertical stress, and the cohesion was larger under high vertical stress. The reason of this phenomenon is more complex, which is mainly related to overconsolidation, unsaturation, and reinforcement of MSW. In the process of sample preparation, it is necessary to apply pressure to the sample, which becomes the preconsolidation pressure, and the sample also becomes overconsolidated soil. The shear strength of overconsolidated soil is nonlinear, which is closely related to the preconsolidation pressure and the current vertical load [29]. For unsaturated soil, the influence of suction can make the shear strength no longer linear [30]. The fiber material in MSW makes it have the characteristics of reinforced soil. Many scholars have studied the reinforced soil and found that the strength of reinforced soil increases faster when the vertical load is small and slower when the vertical load is large [31-33]. Because of the long duration of water soaking in wet method samples, the softening degree of the reinforced fibrous material was high and the strength was low. The reinforcement effect of the fibrous material in the wet method sample was weaker than that in the dry method sample. Therefore, the shear strength envelope of the wet method sample was lower than that of the dry method sample.

3.3. Compression Test. A self-made, one-dimensional, and biodegradable compression instrument was used in this test. Figure 5 shows a schematic diagram of the instrument.

The utilized instrument increased the capacity of the sample container, and both a sealing device and a leachate collection device were set up. The piston vertical rod was used to pressurize the instrument, and the upper part of the vertical rod was welded with the hanger hanging at the pressure weight. The pressure weight was evenly distributed around the hanger.

The diameter of the sample was $8 \mathrm{~cm}$, and the height was $65 \mathrm{~cm}$. The sample was divided into eight layers, which were filled into the container. The initial void ratio of the sample was 2.2. Before adding the sample, the inner wall of the sample container was covered with a plastic film and coated with a lubricant to reduce the influence of friction. The vertical stresses during tests were $1,30,50,100,200,400$, and $800 \mathrm{kPa}$, and the unloading orders were $800,400,200,100$, 50 , and $1 \mathrm{kPa}$, respectively. The stable standard requires that the compression deformation remains below $0.1 \mathrm{~mm} / \mathrm{h}$ for each load. The average test time was 15 days, and degradation may occur during the test. However, previous research results showed that the pure degradation of the organic content in MSW would remain below $10 \%$ over 15 days [34]. This biodegradation is not sufficient, and its effect is not significant over this short period of time. The compression and rebound curves of different samples in $\mathrm{e}-\log \mathrm{p}$ coordinates are shown in Figure 6. The variations of the void ratio are listed in Table 8 , and the compression parameters are listed in Table 9.

Figures 6(a) and 7(b) show that the difference between each compression curve of wet method samples is significant. Each compression curve of dry method samples was 


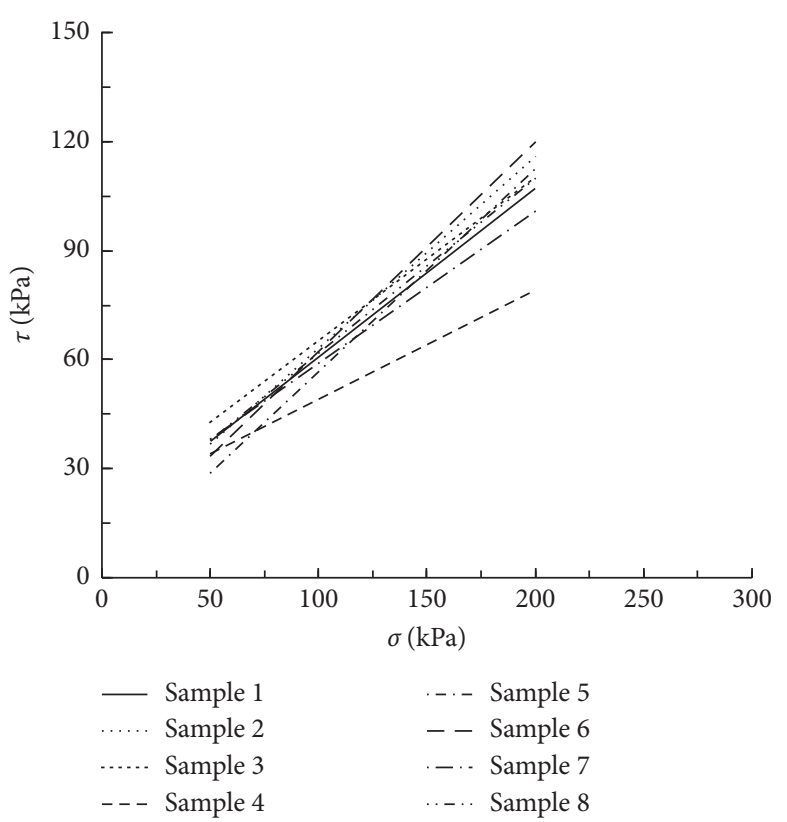

(a)

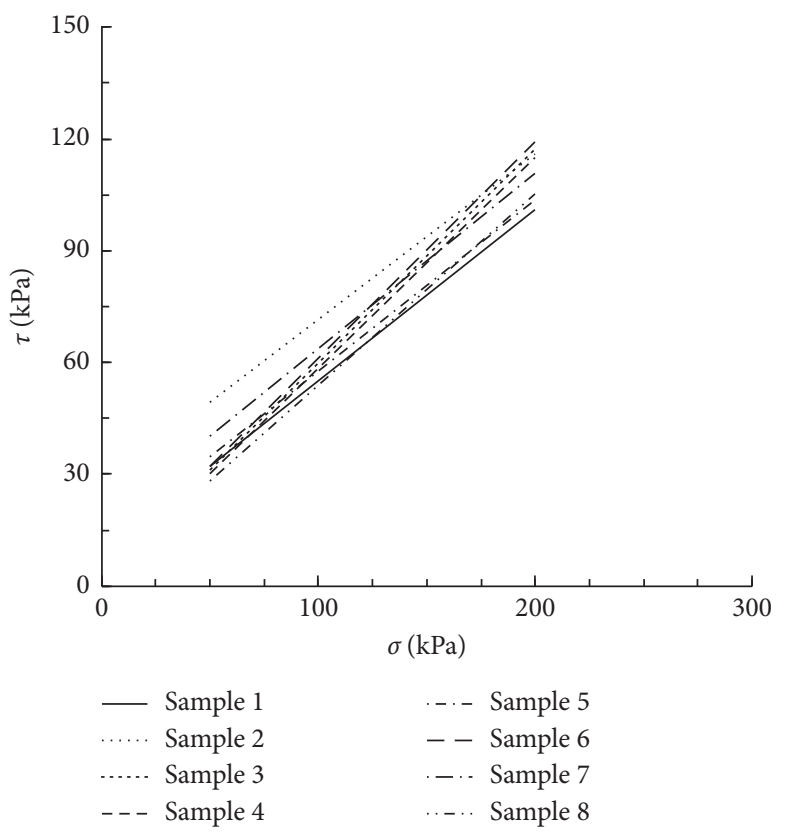

(c)

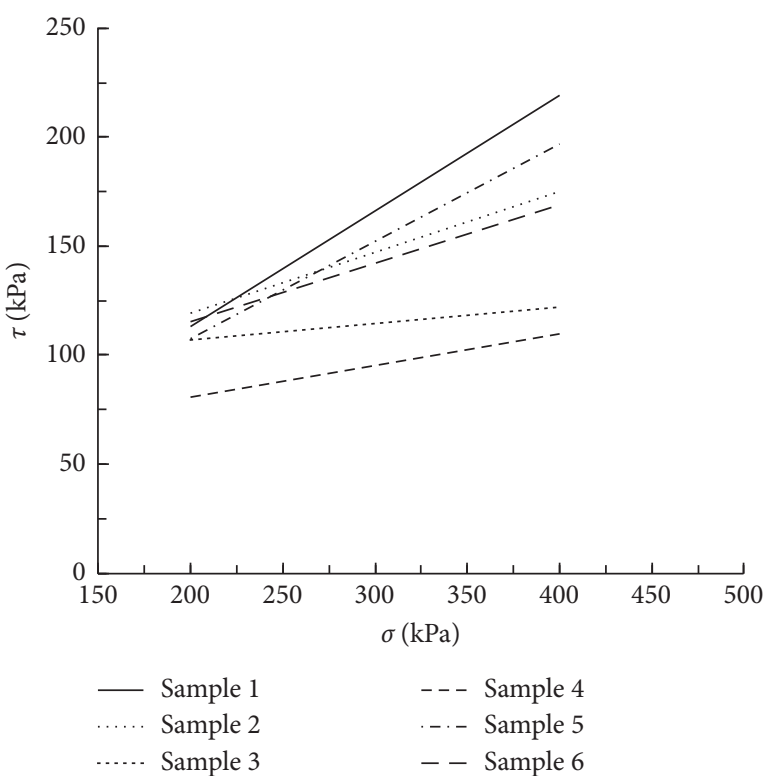

(b)

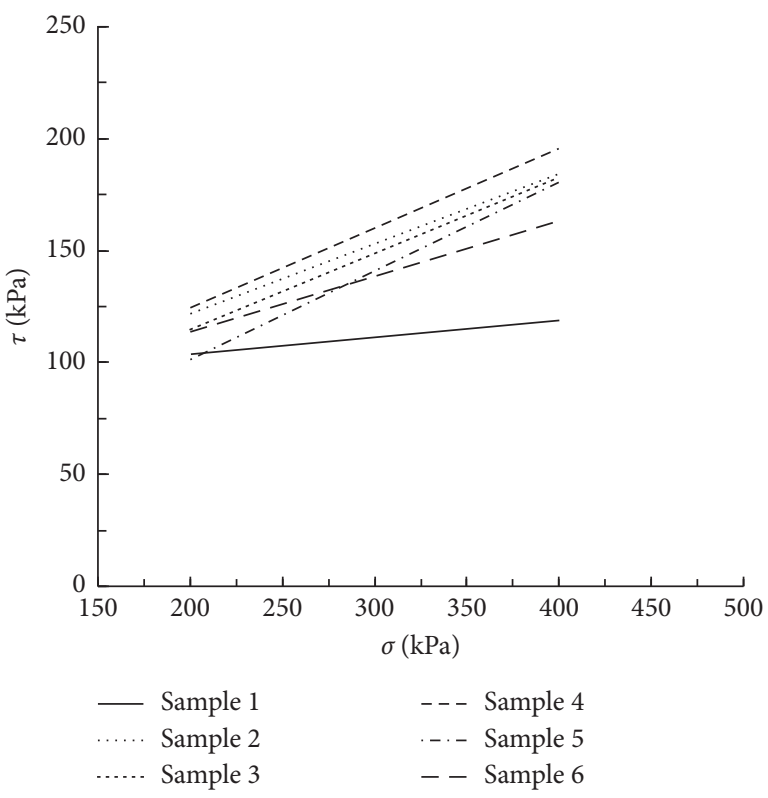

(d)

Figure 3: Shear strength envelopes of different samples under different vertical stress. (a) Wet method samples under 0-200 kPa of vertical stress; (b) wet method samples under $200-400 \mathrm{kPa}$ of vertical stress; (c) dry method samples under 0-200 kPa of vertical stress; (d) dry method samples under $200-400 \mathrm{kPa}$ of vertical stress.

very close. The data dispersion of wet method samples is relatively wide. Tables 8 and 10 verify this observation. The test data average variance of wet method samples was 8.85 times higher than that of the dry method samples.

For dry method samples, since water was added after materials had dried, the amount and the mixing of water can be easily and accurately controlled. The water absorption was uniform, and the water distribution was relatively even. For wet method samples, similar to MSW of the landfill, the water content of each component was inconsistent and the uniformity was poor. Therefore, the test data of wet method samples were more discrete.

The average compression and rebound curves of different sample types are shown in Figure 6(c). The curves of wet and dry method samples are similar, and all test samples showed high compressibility. When the vertical stress remained below $400 \mathrm{kPa}$, the compression deformation of wet method samples was slightly higher. When the vertical stress exceeded $400 \mathrm{kPa}$, the opposite result was obtained. When the vertical stress reached $800 \mathrm{kPa}$, the maximum 
TABLE 6: Cohesion $c$ and angles of internal friction $\varphi$ index values of different samples.

\begin{tabular}{|c|c|c|c|c|c|c|c|c|c|c|}
\hline \multirow{2}{*}{ Sample type } & \multirow{2}{*}{ Index } & \multirow{2}{*}{ Vertical stress $(\mathrm{kPa})$} & \multicolumn{8}{|c|}{ Samples } \\
\hline & & & 1 & 2 & 3 & 4 & 5 & 6 & 7 & 8 \\
\hline \multirow{4}{*}{ Wet method } & \multirow[b]{2}{*}{$\varphi\left(^{\circ}\right)$} & $0-200$ & 24.773 & 27.776 & 24.218 & 16.768 & 29.183 & 29.972 & 23.118 & 25.585 \\
\hline & & $200-400$ & 25.753 & 15.547 & 4.2892 & 8.3682 & 24.008 & 14.928 & $\mathrm{~N} / \mathrm{A}$ & N/A \\
\hline & \multirow{2}{*}{$c(\mathrm{kPa})$} & $0-200$ & 14.602 & 10.459 & 20.388 & 18.922 & 1.018 & 4.585 & 17.243 & 13.989 \\
\hline & & $200-400$ & 18.108 & 63.644 & 92.14 & 51.54 & 26.607 & 71.352 & N/A & $\mathrm{N} / \mathrm{A}$ \\
\hline \multirow{4}{*}{ Dry method } & \multirow{2}{*}{$\varphi\left(^{\circ}\right)$} & $0-200$ & 24.717 & 23.965 & 29.875 & 29.486 & 24.589 & 30.088 & 25.122 & 27.131 \\
\hline & & $200-400$ & 4.340 & 17.276 & 18.716 & 19.55 & 21.569 & 13.961 & $\mathrm{~N} / \mathrm{A}$ & N/A \\
\hline & \multirow{2}{*}{$c(\mathrm{kPa})$} & $0-200$ & 9.083 & 27.015 & 2.523 & 2.031 & 11.954 & 3.283 & 16.878 & 2.702 \\
\hline & & $200-400$ & 88.577 & 59.577 & 47.166 & 53.314 & 22.358 & 64.018 & N/A & N/A \\
\hline
\end{tabular}

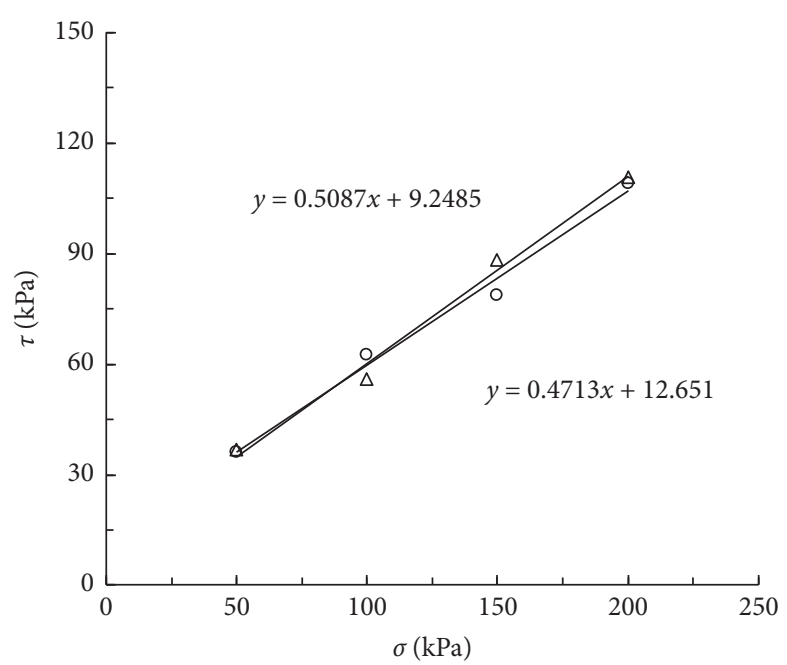

- Wet method sample

$\triangle$ Dry method sample

(a)

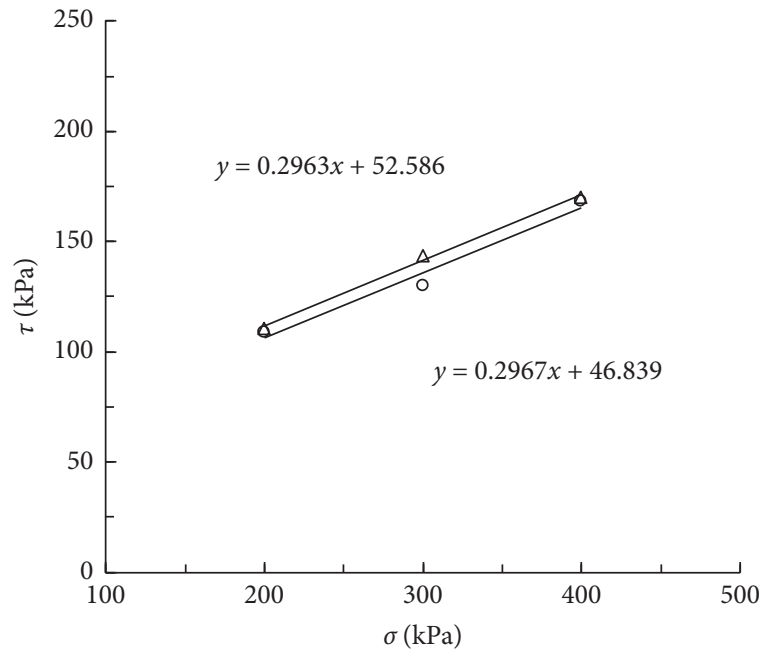

- Wet method sample

$\triangle$ Dry method sample

(b)

Figure 4: Average shear strength envelopes of different sample types. (a) 0-200 kPa vertical stress; (b) 200-400 kPa vertical stress.

TABLE 7: $c$ and $\varphi$ values of the average shear strength envelopes.

\begin{tabular}{lccc}
\hline \multirow{2}{*}{ Samples type } & \multirow{2}{*}{ Index } & \multicolumn{2}{c}{ Vertical stress $(\mathrm{kPa})$} \\
& & $0-200$ & $200-400$ \\
\hline \multirow{2}{*}{ Wet method } & $\varphi\left(^{\circ}\right)$ & 25.247 & 16.534 \\
\multirow{2}{*}{ Dry method } & $\mathrm{C}(\mathrm{kPa})$ & 12.651 & 46.839 \\
& $\varphi\left({ }^{\circ}\right)$ & 26.976 & 16.513 \\
& $\mathrm{C}(\mathrm{kPa})$ & 9.249 & 52.586 \\
\hline
\end{tabular}

difference of the void ratio was $8.9 \%$. The resilience curves of both types of samples are almost parallel, and the difference of the resilience slope was small. Table 9 indicates that the difference in compression parameters between wet and dry method samples was not significant.

In wet method samples, each component always has a certain water content and has not been dried. The soaking time was more sufficient, and the softening degree of the solid skeleton was higher. Therefore, for wet method samples, large deformation affects the initial stage of compression, while for dry method samples, the opposite trend was observed.
In addition, it should be noted that air is easier to drain than water in the sample. When the vertical stress increased, the sample first generated gas, the void was compressed, and the saturation of the sample increased. With continuing compression of the sample, less gas emerged, and the compression of the sample changed from exhaust to drainage. Because the rate of drainage was far less than that of the exhaust, the sample became increasingly difficult to compress, and the increasing ratio of compression deformation was correspondingly smaller. When the vertical stress exceeded $400 \mathrm{kPa}$, the wet method samples were nearly saturated and became difficult to compress. At the same time, the compression amount of the dry method sample was still smaller, the saturation was lower, and the increasing compression deformation ratio was higher.

Moreover, with increasing time and vertical stress, the water in the dry method sample constantly migrated, and the solid skeleton of the sample was softened by the water, leading to a decrease in strength and an increase in compressibility. Therefore, due to the softening of the skeleton and the higher vertical load, the compression deformation of 


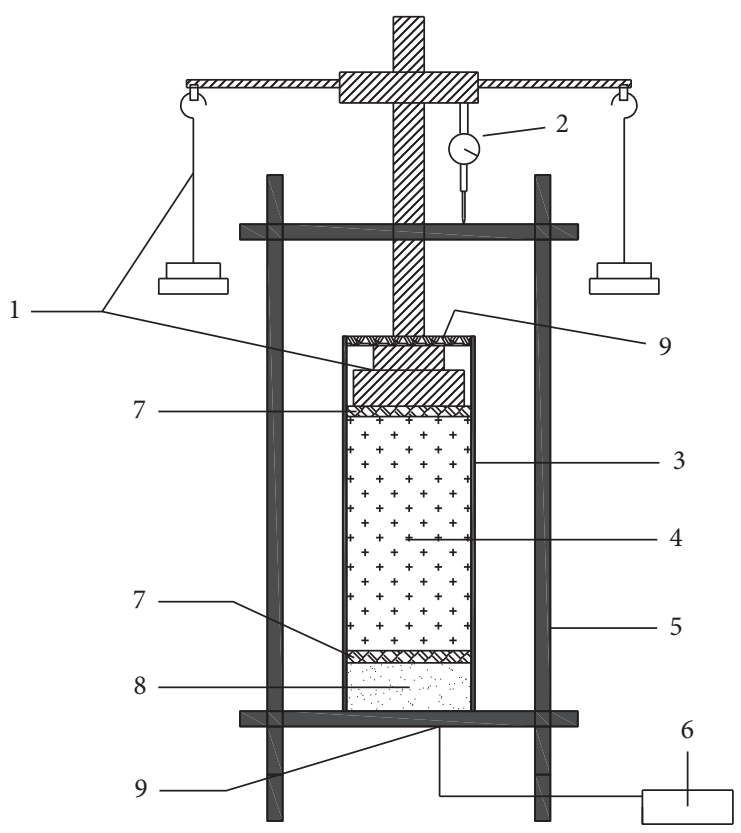

FIGURE 5: One-dimensional biodegradable compression instrument. 1, loading device; 2, measuring device; 3, sample container; 4, sample; 5 , instrument support; 6, leachate collection device; 7, permeable stone; 8 , sand layer; 9, sealing device.
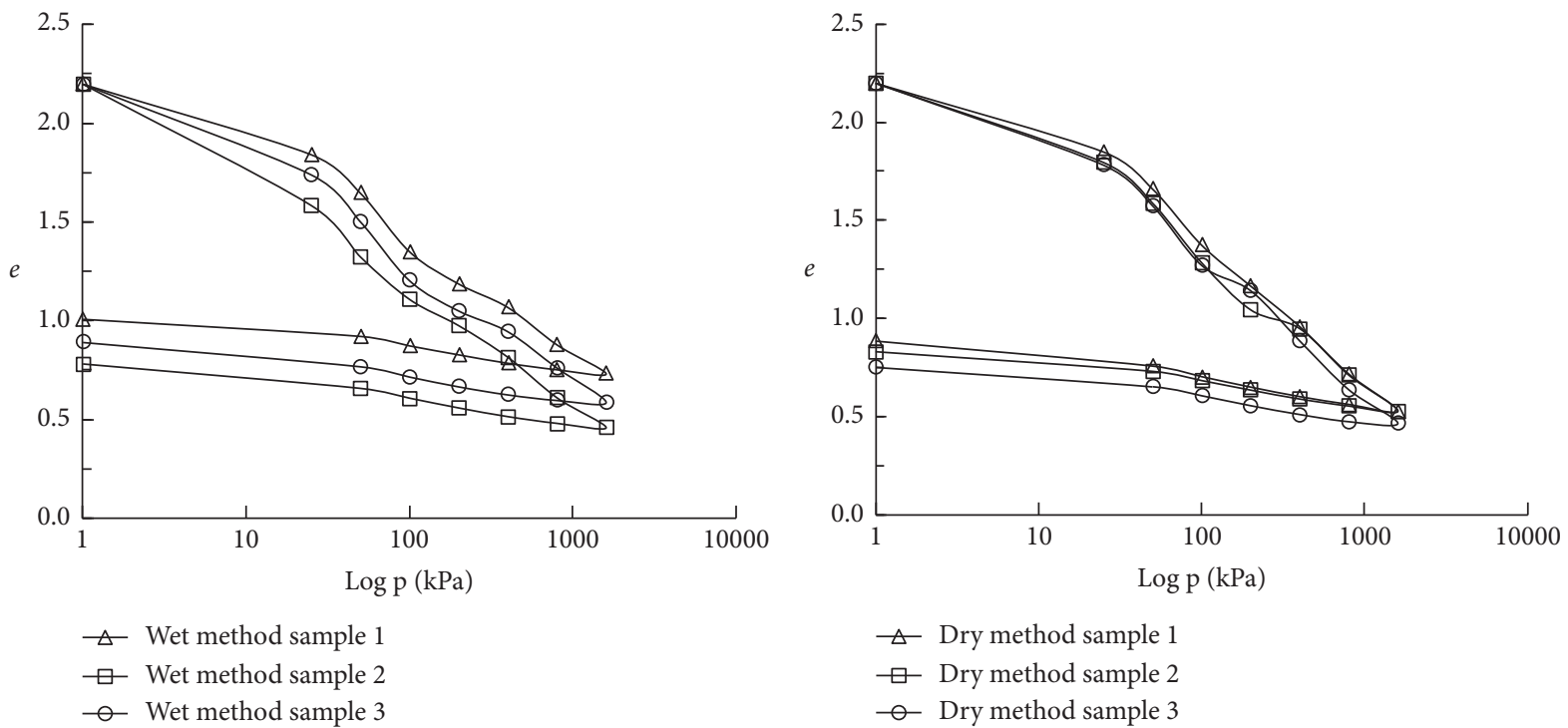

(a)

(b)

FIgURE 6: Continued. 


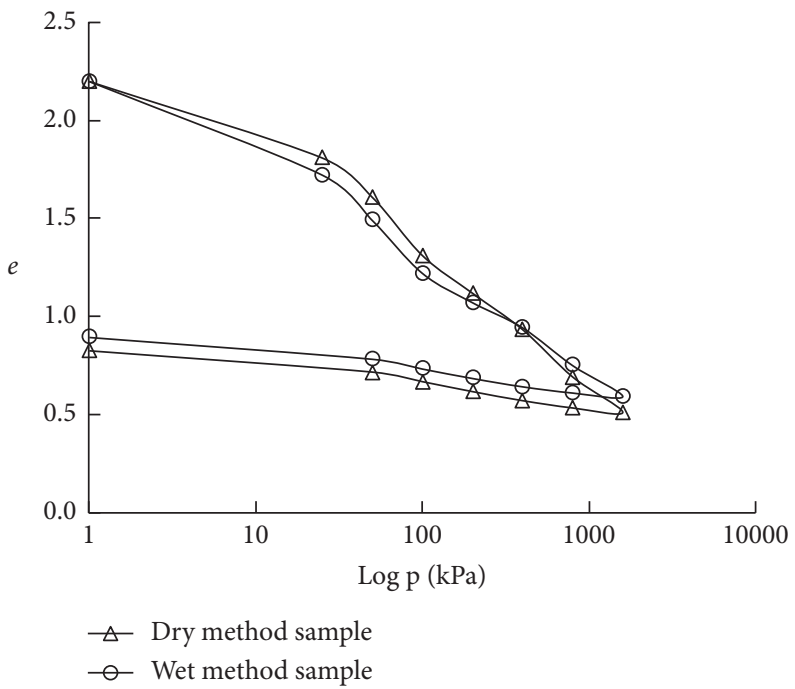

(c)

Figure 6: Compression and rebound curves of different samples in the e-log p coordinate. (a) Wet method samples; (b) dry method samples; (c) average curve comparison.

TABLE 8: Variation of void ratio of different sample types in biodegradation compression tests $\left(\times 10^{-3}\right)$.

\begin{tabular}{lcccccc}
\hline Vertical stress $(\mathrm{kPa})$ & 30 & 50 & 100 & 200 & 400 & 800 \\
\hline Wet method samples & 29.88 & 38.94 & 27.74 & 14.22 & 9.89 & 6.01 \\
Dry method samples & 4.41 & 2.90 & 2.87 & 1.21 & 2.43 & 0.95 \\
\hline
\end{tabular}

TABLE 9: Compression parameters of different samples.

\begin{tabular}{|c|c|c|c|c|c|c|}
\hline \multirow[t]{2}{*}{ Index } & & \multicolumn{3}{|c|}{$\begin{array}{l}\text { Compression coefficient } \\
\left(\mathrm{MPa}^{-1}\right)\end{array}$} & \multirow[t]{2}{*}{ Compression index $C_{\mathrm{c}}$} & \multirow[t]{2}{*}{ Resilience coefficient $\left(\mathrm{MPa}^{-1}\right)$} \\
\hline & & $\mathrm{a}_{1-2}$ & $a_{2-4}$ & $\mathrm{a}_{4-8}$ & & \\
\hline \multirow{4}{*}{ Wet method samples } & 1 & 2.088 & 1.034 & 0.603 & 0.714 & 0.039 \\
\hline & 2 & 2.403 & 0.479 & 0.593 & 0.697 & 0.046 \\
\hline & 3 & 1.296 & 1.278 & 0.622 & 0.698 & 0.044 \\
\hline & Average & 1.929 & 0.930 & 0.606 & 0.703 & 0.043 \\
\hline \multirow{4}{*}{ Dry method samples } & 1 & 1.632 & 0.594 & 0.474 & 0.559 & 0.050 \\
\hline & 2 & 1.333 & 0.802 & 0.514 & 0.593 & 0.043 \\
\hline & 3 & 1.534 & 0.525 & 0.460 & 0.595 & 0.041 \\
\hline & Average & 1.500 & 0.640 & 0.483 & 0.582 & 0.045 \\
\hline
\end{tabular}

the dry method sample exceeded that of the wet method sample when the vertical stress exceeded $400 \mathrm{kPa}$.

3.4. Biodegradation Compression Test. Biodegradability is a special characteristic of MSW. To study the effect of different sample preparation methods on the biodegradability of MSW, biodegradability compression tests were conducted. The test instrument and the vertical stress order are the same for the compression test. The loading time of each pressure degree was 30 days, and the total loading time was 180 days. The biodegradation compression curves of different sample types are shown in Figure 7. The variations of void ratio and compression parameters of different samples in the biodegradation compression tests are shown in Tables 9 and 11, respectively.
Figures $7(\mathrm{a})$ and $7(\mathrm{~b})$ show that similar to the compression test results, the test data discreteness of wet method samples exceeds that of the dry method samples, the reason for which has been explained before. The data in Table 9 and 11 are also consistent with this explanation. The average variation of the test data of the wet method samples is 8.67 times higher than that of the dry method sample.

Figure 7 (c) shows that the average biodegradation compression deformation of the wet method sample is larger and the average void ratio is smaller than that of the dry method sample. The reason is related to the biodegradation environment of different sample types. Degradation is related to microorganisms. Wet method samples always contain water and are rich in microorganisms; thus, these are more likely to provide an internal environment that is 


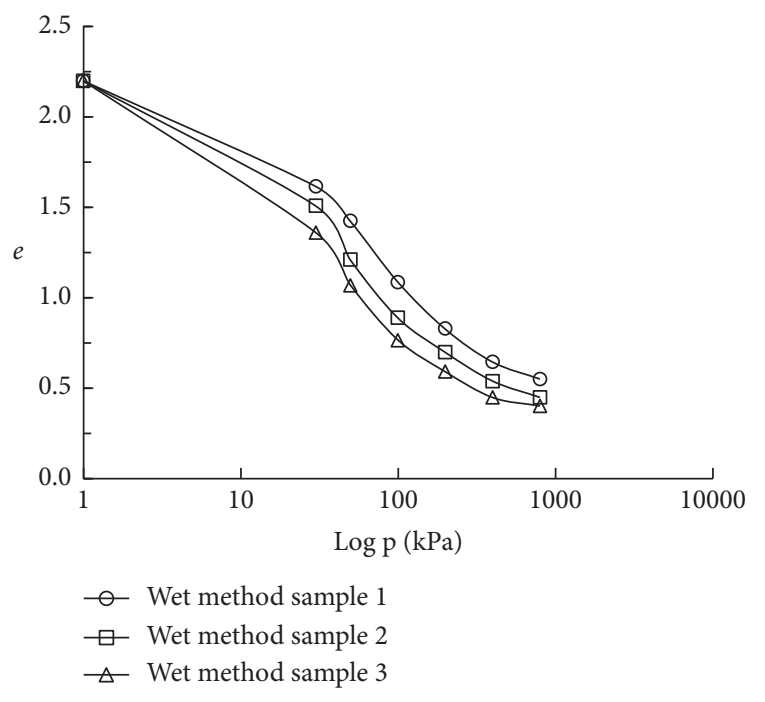

(a)

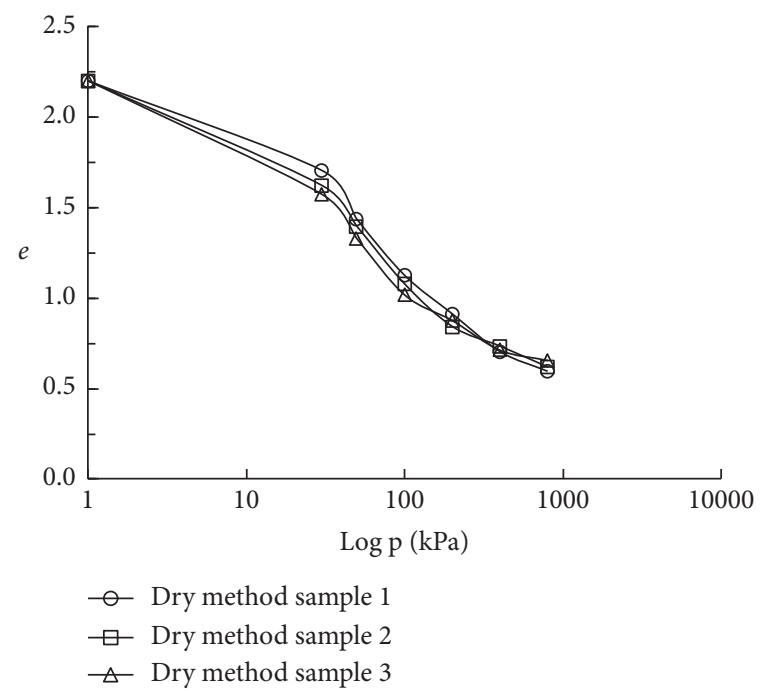

(b)

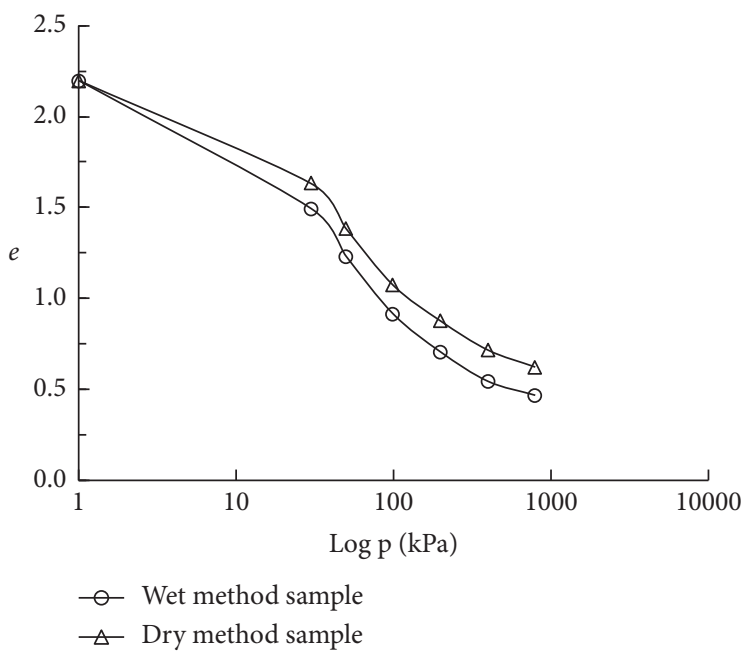

(c)

Figure 7: Biodegradation compression curves of different samples. (a) Wet method samples. (b) Dry method samples. (c) Average curves comparison.

TABle 10: Variance of void ratio of different sample types in compression tests $\left(\times 10^{-3}\right)$.

\begin{tabular}{lcccccc}
\hline Vertical stress (kPa) & 25 & 50 & 100 & 200 & 400 & 800 \\
\hline Wet method samples & 16.87 & 26.30 & 14.93 & 11.62 & 16.16 & 18.36 \\
Dry method samples & 1.26 & 2.09 & 3.14 & 4.12 & 1.55 & 2.01 \\
\hline
\end{tabular}

favorable for biodegradation. The suitable microbial degradation temperature is $41^{\circ} \mathrm{C}$ [35]. Because dry samples need to be dried first, the temperature of $60-70^{\circ} \mathrm{C}$ and the resulting dehydration can strongly reduce microbial activity. Furthermore, when the dried components of dry method samples absorb water again, the distribution and migration of water require a certain time, which requires more time to form a favorable biodegradation environment in the dry method samples. When the test time reached 180 days and the load increased to $800 \mathrm{kPa}$, the maximum difference of the void ratio between the wet and dry method samples was $33.7 \%$, which is a significant difference.

Figure 8 shows a comparison of the compression curve and biodegradation compression curve, and a comparison of compression parameters is shown in Table 12. The effect of biodegradation on compressive properties is reflected in these comparisons.

Since the biodegradation compression test takes longer, the biodegradation causes more compression deformation. Therefore, the biodegradation compression curve always remained below the compression curve, and the maximum difference of the void ratio was $73.5 \%$ for wet method samples and $29.8 \%$ for dry method samples.

Regardless of whether samples were prepared as a wet or dry method sample, the compression coefficient of the biodegradation compression curve was larger at the initial stage, similar at the middle stage, and significantly different during the late period. Therefore, the difference of the void ratio 
TABLE 11: Biodegradation compression parameters of different samples.

\begin{tabular}{|c|c|c|c|c|c|}
\hline \multirow{2}{*}{ Sampl } & & \multicolumn{3}{|c|}{ Compression coefficient $\left(\mathrm{MPa}^{-1}\right)$} & \multirow{2}{*}{ Compression index $C_{\mathrm{c}}$} \\
\hline & & $a_{1-2}$ & $a_{2-4}$ & $\mathrm{a}_{4-8}$ & \\
\hline \multirow{4}{*}{ Wet method samples } & 1 & 2.596 & 0.912 & 0.235 & 0.312 \\
\hline & 2 & 1.902 & 0.797 & 0.225 & 0.299 \\
\hline & 3 & 1.758 & 0.714 & 0.117 & 0.156 \\
\hline & Average & 2.085 & 0.808 & 0.192 & 0.256 \\
\hline \multirow{4}{*}{ Dry method samples } & 1 & 2.122 & 1.040 & 0.272 & 0.361 \\
\hline & 2 & 2.343 & 0.541 & 0.288 & 0.383 \\
\hline & 3 & 1.410 & 0.817 & 0.141 & 0.187 \\
\hline & Average & 1.958 & 0.799 & 0.234 & 0.310 \\
\hline
\end{tabular}

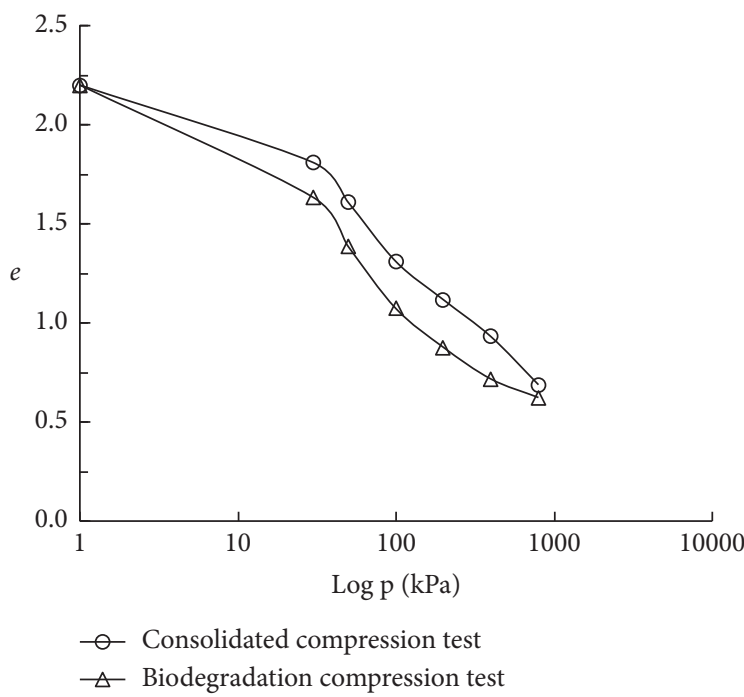

(a)

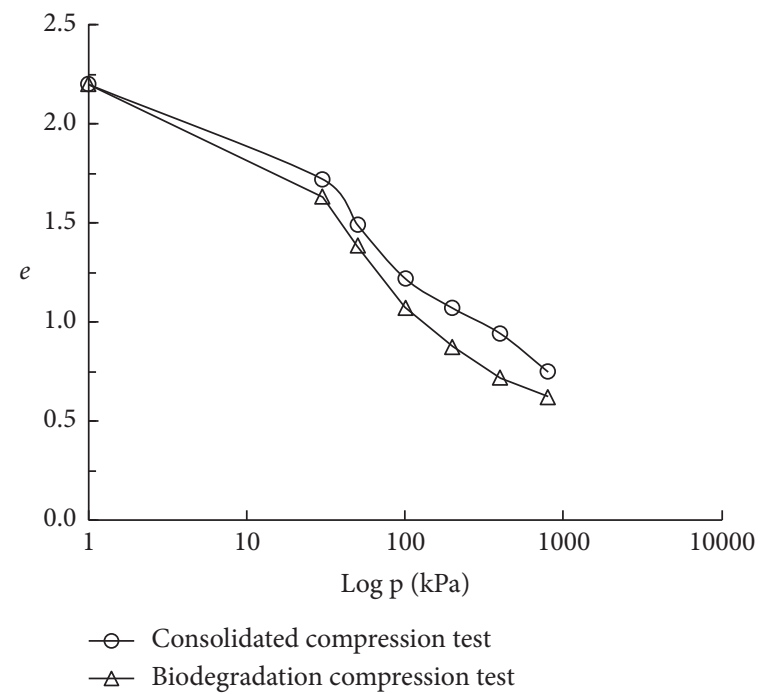

(b)

Figure 8: Comparison of average curves between the compression test and the biodegradation compression test. (a) Wet method samples; (b) dry method samples.

TABLE 12: Comparison of parameters between the compression test and the biodegradation compression test.

\begin{tabular}{lccccc}
\hline & \multirow{2}{*}{ Index } & \multicolumn{2}{c}{ Compression coefficient $\left(\mathrm{MPa}^{-1}\right)$} & \multicolumn{2}{c}{ Compression index $C_{\mathrm{c}}$} \\
& & $\mathrm{a}_{1-2}$ & $\mathrm{a}_{2-4}$ & $\mathrm{a}_{4-8}$ & \\
\multirow{2}{*}{ Wet method samples } & Compression test & 1.929 & 0.930 & 0.606 & 0.703 \\
& Biodegradation compression test & 2.085 & 0.807 & 0.192 & 0.256 \\
\multirow{2}{*}{ Dry method samples } & Compression test & 1.500 & 0.640 & 0.483 & 0.582 \\
& Biodegradation compression test & 1.958 & 0.799 & 0.234 & 0.310 \\
\hline
\end{tabular}

between the biodegradation compression curve and the compression curve gradually increased at the initial stage, peaked at the middle stage, and gradually decreased at the later stage. At the end of the biodegradation compression test, biodegradation has sufficiently occurred, and the compressibility of the sample was reduced. However, the compression test time was short, the degree of biodegradation was low, and the compressibility was relatively high. The results of the compression parameter value also confirmed this result.

The result of the biodegradation compression test identified biodegradation as an important factor that affects the compressibility of waste, and the sufficient biodegradation results in a significant compression deformation of the waste. Since the biodegradation was more sufficient in wet method samples, the difference between the biodegradation compression curve and the compression curve was also larger when compared with the dry method sample.

\section{Conclusions}

Laboratory tests are indispensable for the study of MSW. The method of sample preparation is the most basic and important part of such laboratory tests. To study the effect of sample preparation method on the results of MSW engineering characteristic tests, the direct shear test, compression test, and biodegradation compression test were conducted on dry and wet method samples, and the following conclusions were obtained from the test results. 
The MSW of Xi' an has the characteristics of large porosity, high water content, and high compressibility. In the direct shear test and compression test, the dispersion of test data of wet method samples exceeded that of the dry method samples. However, the differences between the average test values of both samples were not significant. The difference of cohesive forces between dry and wet method samples was $12.3 \%$, and the difference of their void ratios was $8.9 \%$. These differences were not significant. The biodegradation compression test showed a larger data dispersion for wet method samples. The deformation of wet method samples was higher. The final void ratio of wet method samples was $33.7 \%$ higher than that of the dry method samples, and the difference was significant. Comparing the biodegradation compression curve with the compression curve shows that the void ratio of the biodegradation compression curves of both methods was smaller because of the biodegradation effect. The maximum difference of the void ratio was $73.5 \%$ for wet method samples and $29.8 \%$ for dry method samples. The effect of biodegradation on the test results was significant.

According to the results of this study, the sample preparation method for soil, as outlined in the traditional geotechnical standard, should not be used for MSW without judgment. Suitable sample preparation methods for MSW can effectively improve the convenience and accuracy of the required tests. For the direct shear test and the compression test, the effect of biodegradation remained relatively small. The average test results of dry method samples were similar to those of wet method samples. Because dry method samples are easy to control and prepare and their test dispersion is small, their use enables accurate results with fewer samples. Therefore, these are more suitable to prepare samples for tests in which biodegradation is not the main influencing factor. When dry method samples are prepared, sufficient time should be budgeted for water migration and infiltration to minimize test deviation. Biodegradation compression tests showed that the effect of biodegradation is significant, and the average test results of dry method samples differed from those of wet method samples. Therefore, it is more appropriate to choose wet method samples for tests in which biodegradation is the main influencing factor. These can more accurately reflect the biodegradation characteristics of MSW.

\section{Data Availability}

The data used to support the findings of this study are available from the corresponding author upon request.

\section{Conflicts of Interest}

The authors declare that there are no conflicts of interest regarding the publication of this paper.

\section{Acknowledgments}

This work was supported by the Shaanxi Natural Science Foundation Project (grant number 2020JM-235); Shaanxi Postdoctoral Research Funding Project (grant number
2017BSHEDZZ114); Open Project of State Key Laboratory of Green Building in Western China (grant number LSKF201905); Science and Technology Planning Project of Yulin Technology Division (grant number 214028170376); and Scientific Innovation Practice Project of Postgraduates of Chang'an University (grant numbers: 300103002097 and 300103002094).

\section{References}

[1] S. Kaza, L. Yao, P. B. Tata, and F. V. Woerden, What a Waste 2.0: A Global Snapshot of Solid Waste Management to 2050, World Bank Group, Washington, DC, USA, 2018.

[2] National Bureau of Statistics of China, China Statistical Yearbook, China Statistics Press, Beijing, China, 2013.

[3] J. Li, Y. Zhou, and Y. Y. Liu, "Current situation and prospect of disposal of solid waste in cities in China," Urbanism and Architecture, vol. 2018, no. 17, pp. 88-91, 2018.

[4] J. Tai, M. An, and X. D. Wang, Annual Research Report on the Development of Urban Environmental and Sanitation Industry in China (2016-2017), Shanghai Jiao Tong University Press, Shanghai, China, 2016.

[5] Shaanxi Provincial Bureau of Statistics, Shannxi Statistical Yearbook, China Statistics Press, Beijing, China, 2010.

[6] F. Castelli and V. Lentini, "Dynamic characterization of municipal solid waste by in situ and laboratory tests," Journal of Geotechnical and Geoenvironmental Engineering, vol. 143, no. 5, Article ID 06017002, 2017.

[7] B. J. Ramaiah, G. V. Ramana, and M. Datta, "Mechanical characterization of municipal solid waste from two waste dumps at Delhi, India," Waste Management, vol. 68, pp. 275-291, 2017.

[8] K. Reddy, H. Hettiarachchi, J. Gangathulasi, J. Bogner, and T. Lagier, "Geotechnical properties of synthetic municipal solid waste," International Journal of Geotechnical Engineering, vol. 3, no. 3, pp. 429-438, 2009.

[9] Y. R. Zhao and Y. X. Zhang, Study on the Mechanical and Biodegradation Settlement Properties of Municipal Solid Waste, Chongqing University, Chongqing, China, 2014.

[10] P. B. Yuan, Large-scale Simple Shear Testing of Municipal Solid Waste, Lanzhou University, Lanzhou, China, 2011.

[11] D. Y. Liu, "Research on the effect of water contents on degradation of organic matter in municipal solid waste," Earth and Environment, vol. 38, no. 01, pp. 26-30, 2010.

[12] Ministry of Housing and Urban Rural Development of the People's Republic of China, Technical Specification for Soil Test of Landfilled Municipal Solid Waste (CJJ/T204-2013), China Architecture \& Building Press, Beijing, China, 2013.

[13] Ministry of Housing and Urban Rural Development of the People's Republic of China, Technical Code for Geotechnical Engineering of Municipal Solid Waste Sanitary Landfill (CJJ176-2012), China Architecture \& Building Press, Beijing, China, 2012.

[14] Ministry of Housing and Urban Rural Development of the People's Republic of China, Standard For Soil Test Method (GB/T 50123-2019), China Planning Press, Beijing, China, 2019.

[15] S. J. Feng, Static and Dynamic Strength Properties of Municipal Solid Waste and Stability Analysis of Landfill, Zhejiang University, Hangzhou, China, 2005.

[16] S. J. Feng, C. M. Yun, X. J. Kong, and D. G. Zou, "Experimental research on dynamic properties of municipal solid 
waste," Chinese Journal of Geotechnical Engineering, vol. 27, no. 7, pp. 750-754, 2005.

[17] M. K. Singh, J. S. Sharma, and I. R. Fleming, "Shear strength testing of intact and recompacted samples of municipal solid waste," Canadian Geotechnical Journal, vol. 46, no. 1, pp. 1133-1145, 2009.

[18] J. L. Hanson, N. Yesiller, S. A. Von Stockhausen, and W. W. Wong, "Compaction characteristics of municipal solid waste," Journal of Geotechnical and Geoenvironmental Engineering, vol. 136, no. 8, pp. 1095-1102, 2010.

[19] A. O. Landva, A. J. Valsangkar, and S. G. Pelkey, "Lateral earth pressure at rest and compressibility of municipal solid waste," Canadian Geotechnical Journal, vol. 37, no. 6, pp. 1157-1165, 2000.

[20] M. S. Hossain, M. A. Gabr, and M. A. Barlaz, "Relationship of compressibility parameters to municipal solid waste decomposition," Journal of Geotechnical and Geoenvironmental Engineering, vol. 129, no. 12, pp. 1151-1158, 2003.

[21] K. R. Reddy, J. Gangathulasi, N. S. Parakalla, H. Hettiarachchi, J. E. Bogner, and T. Lagier, "Compressibility and shear strength of municipal solid waste under short-term leachate recirculation operations," Waste Management \& Research, vol. 27, no. 6, pp. 578-587, 2009.

[22] C. A. Bareither, C. H. Benson, and T. B. Edil, "Compression behavior of municipal solid waste: immediate compression," Journal of Geotechnical and Geoenvironmental Engineering, vol. 138, no. 9, pp. 1047-1062, 2012.

[23] D. Zekkos, J. D. Bray, E. Kavazanjian et al., "Unit weight of municipal solid waste," Journal of Geotechnical and Geoenvironmental Engineering, vol. 132, no. 10, pp. 1250-1261, 2006.

[24] N. Yang, L. M. Shao, and P. J. He, "Study on the moisture content and its features for municipal solid waste fractions in China," China Environment Science, vol. 38, no. 3, pp. 1033-1038, 2018.

[25] Y. P. Wu and S. C. Dong, "Status and prospect of current municipal solid waste treatment technology-on visual point adjustment of municipal solid waste policy in China," Urban Environment \& Urban Ecology, vol. 14, no. 1, pp. 33-36, 2001.

[26] J. Prabakar and R. S. Sridhar, "Effect of random inclusion of sisal fibre on strength behaviour of soil," Construction and Building Materials, vol. 16, no. 2, pp. 123-131, 2002.

[27] N. C. Consoli, M. D. T. Casagrande, P. D. M. Prietto, and A. N. Thomé, "Plate load test on fiber-reinforced soil," Journal of Geotechnical and Geoenvironmental Engineering, vol. 129, no. 10, pp. 951-955, 2003.

[28] C. F. Chen, H. X. Liu, and Y. P. Li, "Experiment investigation on reinforcement mechanism and strength criterion of grassroots reinforced soils," Journal of Central South Highway Engineering, vol. 31, no. 2, pp. 1002-1205, 2006.

[29] S. Wei, W. J. Zhang, S. X. Xiao, and Q. Chen, "Mechanical properties of saturated clay under effect of over consolidation ratio," Journal of Chongqing Jiaotong University (Natural Science), vol. 36, no. 5, pp. 64-70, 2017.

[30] F. Wei and L. Wan, "Study on nonlinear shear strength of unsaturated soil based on van Genuchten model," Chinese Journal of Applied Mechanics, vol. 36, no. 5, pp. 1220-1227, 2019.

[31] J. H. Ding and J. Tong, "Application of a multifunctional soilgeosynthetics testing machine to research on soil-geogrid interaction," Journal of Yangtze River Scientific Research Institute, vol. 34, no. 2, pp. 29-34, 2017.
[32] S. H. Chen, "Study of direct shear test and pull-out test in reinforced material with clay engineering," Liaoning Communications Technology, vol. 25, no. 11, pp. 17-19, 2005.

[33] H. W. Wei, Z. H. Yu, and Y. H. Zou, "Shear characteristics of soil reinforced with geosynthetic material," Shuili Xuebao, vol. 36, no. 5, pp. 555-562, 2005.

[34] Y. D. Hu and J. Y. Shi, Regularity of Biodegradation in Municipal Solid Waste and Its Influence for Deformation of Municipal Solid Waste, Hohai University, Nanjing, China, 2006.

[35] M. A. Barlaz, M. W. Milke, and R. K. Ham, "Gas production parameters in sanitary landfill simulators," Waste Management \& Research, vol. 5, no. 1, pp. 27-39, 1987. 